\title{
Students Wellness: Mental Health
}

Skylar Robinson

As college students, it isn't easy to maintain our mental health while focusing and excelling in school. Mental health is an important issue to discuss among students, as problems can potentially lead to stress, anxiety, depression, suicidal thoughts, and eating disorders. Below are some tips to help students deal with their mental health.

Do activities and hobbies that you enjoy; doing this can improve your mental and psychological well-being. Give yourself time away from school and focus on doing other things outside of academic work. Activities such as attending local art therapy classes, including painting, sculpting, or drawing, help you to express yourself and improve your mental health. Other activities, such as yoga, walking, meditating, dancing, and playing sports with friends, can drastically improve your mental health. Giving yourself 15 minutes to an hour every day to get away to attend art therapy or exercise could be beneficial for students.

The most crucial tip is to seek help from a professional if needed. Students might feel uncomfortable or ashamed to get help, and it's important to know that it's okay to talk to someone. UTA provides free psychological and counseling services, called CAPS, and accommodations for students. CAPS offers mental health services by providing individual and group counseling. Students are given free sessions during the semesters; counselors develop a personal plan to help students cope with their mental health. Finally, UTA provides accommodations for students struggling with their mental health with the Student Access \& Resource Center. Students must receive documentation from their physician confirming theirtreatment for their mental health. Accommodations can include the ability to record lectures, extra time for exams, and taking exams outside of their courses in an isolated room in the SARS Office.

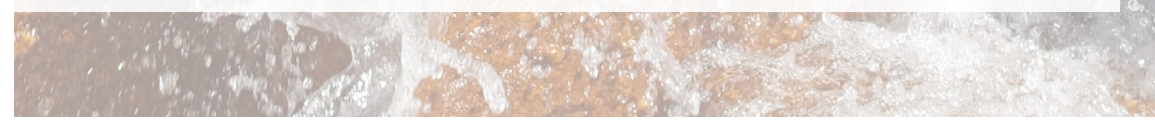

24 HOUR MAVS TALK CRISIS LINE 817-272-8255

\section{PSYCHIATRY \& HEALTH SERVICES} 605 W. 1st Street Arlington, TX 76019 817-272-2771 